\title{
Visitors' Preferences for Museum Interpretation: Identifying and Targeting Market Segments
}

\author{
Gorazd Sedmak \\ University of Primorska, Faculty of Tourism Studies - Turistica, Slovenia \\ gorazd.sedmak@fts.upr.si \\ Aleksandra Brezovec \\ University of Primorska, Faculty of Tourism Studies - Turistica, Slovenia \\ aleksandra.brezovec@fts.upr.si
}

A number of heritage studies have revealed that interpretation is an essential component of the visitor experience. However, visitors differ in their interests in interpretation. Preferences for interpretation, which are often neglected in the literature, are essential for the marketing and management of heritage organisations. This paper deals with visitors' preferences for museum interpretation to determine what the preferred types of interpretation of museums exhibits are and what the differences between the segments of visitors in this regard are. The research focuses on seven Adriatic heritage museums that took part in the cross-border project on the strengthening of cultural tourism through market-oriented initiatives. The survey set out to obtain information on visitor profiles and their preferences for museum interpretation. By isolating and analysing interpretation variables and visitor variables associated with visitor interpretation preferences, a framework was developed that enable the initiatives in museum interpretation for target market segments.

Keywords: interpretation, museum, visitors, segmentation, Adriatic.

https://doi.org/10.26493/2335-4194.10.141-150

\section{Introduction}

Modern museums have typically been multi-functional institutions, supposed to be authoritative holders and producers of knowledge, sources of 'the right' interpretation, and dominant narratives through placebased exhibitions (Keene, 2005). They collect, preserve and protect heritage and culture, and disseminate knowledge, however, increasingly there is a challenge in attracting visitors and satisfying their expectations (Packer \& Ballantyne, 2002; Trinh \& Ryan, 2013). All in all, they have to make their operation financially sustainable, which can be extremely difficult considering the diverse range of goals they should pursue (Blattberg \& Broderick, 1991; McLean, 1997). Especially, after the 1970s, when declines in funding from the state budgets took place, museums were increasingly forced to partially finance themselves from fees and other earnings from the market (Goulding, 2000; Maier, 1999). Marketing scholars outline three strategies for effective museum marketing: improving museum experiences, improving community service and market repositioning toward entertainment (Kotler, Kotler, \& Kotler, 2008). As 'classical' museums did not have adequate marketing personnel, and the curatorial staff was reluctant about 'mass marketing' (Blattberg \& Broderick, 1991), a quite stressful search for a way to survive in new circumstances began.

Thyne (2001) justly claims that despite museums are usually not linked to concepts of profitability and competitiveness they still have to provide the best cus- 
tomer service. Therefore, they need to understand different segments of visitors regarding their demographic and psychographic traits. To gain an overview of museum use, a summary of the findings of museum visitor surveys have been made. Macdonald (2011, p. 368) reported 'the typical museum visitor' was in the upper education, occupation and income groups, usually looking for opportunities to learn, to experience something new, to do something worthwhile, to feel ease and comfort, and also to participate actively. According to Rounds (2004), only a minor part of visitors attend the exhibitions in a thorough manner. What they attempt to achieve is the maximisation of their 'Total Interest Value' of the museum visit by focusing on 'those exhibit elements with high interest value and low search costs.' The extremely fast development of new technologies further accelerated these processes. Virtual demonstrations and displays and other computer-based interpretations of culture and heritage have nowadays become almost indispensable parts of exhibitions (Rentschler \& Hede, 2007; Staiff, 2014).

In last three decades, some other important changes on the market have occurred. A wide variety of new museums, theme houses, amusement and experiment houses emerged, that made the competition in the field much more severe and considerably changed expectations of museum visitors (Blattberg \& Broderick, 1991; Kotler et al., 2008). They have become more 'market-driven' (McLean, 1997; Marstine, 2008), demanding and critical in respect to the contents, interpretation and the 'augmented product.' The new interpretative approach advocates an aesthetic experience and turns museums into 'creative spaces' for object-human communication (Dudley, 2010). Furthermore, 'visitors' motives have been moving away from museums idealized agendas' (Roppola, 2012, p. 47). Pleasure, curiosity, 'learning for fun' and 'being with friends and family' have generally become a more appropriate base for the conceptualization of exhibitions than 'serious pursuit for knowledge' (Thyne, 2001). In the early 1980s, Koran and Koran (1986, p. 12) claimed that 'a large percentage of visitors are there to "kill time," to be entertained, to satisfy curiosity, or to "people watch."
Museum visitors, however, are not homogeneous and not all of them reacted the same way to the changes and adoption of the 'product.' Thus, distinctions between the segments and a differentiated approach have today become even more important than in the past. This is true for domestic visitors as well as for foreign tourists. While in the past, significant efforts had been placed on psychographic tourist classification (Cohen, 1979; Poon, 1998; Plog, 2001), this was not the case for domestic museum visitors. We believe, however, the findings from tourism can be easily transferred to the field of museums, as there is a strong connection between heritage and tourism. 'Heritage and tourism are collaborative industries, heritage converting locations into destinations and tourism making them economically viable,' claims KirchenblattGimblett (as quoted in Marstine, 2008, p. 12). Apostolakis (2003) further analysed the 'convergence between tourism and heritage' as a 'consumer-driven process', where a central role in determining what museums offer in their exhibits, is given to audiences. With a consumer-driven approach, marketing operations in a heritage tourism context are directed towards repackaging the museum product to make it more appealing and accessible to the tourism market. However, tourists are a specific segment of museum visitors and should be treated differently than domestic visitors (Stylianou-Lambert, 2011).

Since the late 1970s, when Cohen (1979) proposed one of the first tourist psychographic typologies, it became clear tourists seek different experiences on their travels. Of course, the plural character of tourist experiences is also present among the cultural tourists (Dolnicar, 2002). Typically, differences can be found in the reasons for visiting heritage sites (Poria, Butler, \& Airey, 2004), interests (Hughes, 2002), the degree of motivation for visiting exhibitions (Silberberg, 1995), the degree of emotional involvement due to connection with their own heritage (Poria, Reichel, \& Biran, 2006), the depth of experience sought and the willingness for an active engagement (McKercher, 2002), the effectiveness of various media (Noor, Mostafa, Vithya, \& Mastura, 2015), and the reception of heritage communication (Groote \& Haartsen, 2016). Thus, from the marketing point of view, knowledge on and un- 
derstanding of different segments seem to be a prerequisite for sensible marketing and, consequently, a satisfactory experience. Intuitively, this is true also for the museum visitors. In fact, Todd and Lawson (2001) determined that everyday life habits considerably influence museum visitors behaviour and expectations. As heritage interpretation is a social and cultural process' (Staiff, 2014, p. 3), it should be hypothesised and explained about everyday life.

Most previous museum visitor studies have focused on the behaviour, experiences, attitudes, and opinions of actual and potential visitors. Authors (e.g. Hooper-Greenhill, 1994; Chen, Chuan, \& Ming, 2006; Falk, 2013; Groote \& Haartsen, 2016) argue different museum visitors need different provisions - different types of exhibitions, different functions, different sizes and different approaches to interpretation. Interpretation is defined as a communication tool that is used to facilitate the way(s) visitors engage with museum exhibits (Wearing, Edinborough, Hodgson, \& Frew, 2008). Different authors (e.g. Packer \& Ballantyne 2002; Wearing et al. 2008; Trinh \& Ryan 2013; Groote \& Haartsen, 2016) pointed out the need for greater attention in the research on museum interpretation, which is of huge importance affecting the museum visitors' experience and satisfaction.

Many conceptual frameworks have been developed for effective museum interpretation. Tilden (1977), for example, focused on the role of the guide, Ham (1992) emphasised the content and style of interpretation, while Moscardo, Fesenmaier, Uysal, and Joseph (1999) focused on the role of visitors' personal factors. Silverman (1995) pointed out the visitor's active role in creating the meaning of a museum experience, influenced by leisure motivations, companions and selfidentity. Dudley (2010) studied the way information had been fetishised in museum and heritage places. As suggested by Wearing et al. (2008), museums would need to take a much greater account of visitors' characteristics, and a more segmented approach to exploring interpretation experiences. In the age of experience economy, when interpretation engages individuals in a personal way, the overall value of visitor experience can be understood by the ratio of the experience satisfaction and the 'sacrifice' (time, effort), claims Bitgood and Dukes (2006, 2). As museum interpretation affects both variables, it is clear that the consolidated effect is very significant. The focus of the present study is thus on the preferences for museum interpretation among different segments of visitors.

Through quantitative analysis, the authors of this study aimed to determine what the preferred types of interpretation of chosen natural heritage museums exhibits are and what the differences between the segments of visitors in this regard are. Based on this information, a framework was developed that enables the optimisation of museum interpretation for target market segments.

\section{Methodology}

The data were obtained during the Museumcultour cross-border project through face-to-face survey research among visitors to seven Adriatic natural heritage museums in Italy, Slovenia and Croatia (all museums taking part in the project): Sea Museum in San Benedetto del Tronto, Italy $(n=80)$, Ecomuseum of Argenta in Ferrara, Italy $(n=25)$, Knowledge centre in Postojna, Slovenia $(n=83)$, Natura Museum in Ravenna, Italy $(n=29)$, Natural History Museum in Rijeka, Croatia $(n=92)$, The Wood and Deer Museum of Mesola in Ferrara, Italy $(n=20)$ and Comacchio museum, Italy $(n=20)$. All museum visitors present during the survey which were willing to participate were included in the survey. The final sample size was 349 .

In addition to questions on interpretation and socio-demography, several questions on psychographic and behavioural characteristics, such company on the travel, the motive for visiting the museum, the main motive for the travel, previous visits to the museum, etc. were included in the questionnaire. Motivation seems to be an important factor influencing preferences regarding interpretation. Packer and Ballantyne (2002) claim motivational factors and the situational characteristics, such as personal goals, beliefs, opportunities for learning etc. do have an impact on the selective direction of behaviour. Therefore, they believe it is plausible that different interpretation is suitable for visitors with different motives. Poria et al. (2004) identified three main reasons for visiting heritage sites: 
Table 1 Adequacy of Interpretation Type

\begin{tabular}{|c|c|c|c|}
\hline Interpretation type & $N$ & $\bar{x}$ & $\sigma$ \\
\hline In-person guiding provided by tour guides - interpreters & 308 & 4.10 & 0.98 \\
\hline Acted-out scenes & 283 & 3.76 & 1.03 \\
\hline Those that require my active involvement & 297 & 3.71 & 1.16 \\
\hline Computer-supported, technologically advanced shows/displays ( $3 \mathrm{D}$, multivision, etc.) & 305 & 3.63 & 1.08 \\
\hline Audio guides & 278 & $3 \cdot 37$ & 1.16 \\
\hline
\end{tabular}

'heritage experience,' 'learning experience,' and 'recreational experience.' The range of motives, however, seem to be even broader, ranging from nostalgia (Jewell \& Crotts 2002), 'just to spend some time,' 'staying in good company' (Thyne, 2001) to 'accidental' visits (Silberberg, 1995). Falk (2013) proposed clustering all the various motivations of museum visitors into five identity-related categories: explorers, hobbyists, facilitators, experience seekers, and rechargers. These motivations are a direct reflection of how the public perceives the reasons for visiting the museum.

Because the museums taking part in the research exhibit natural heritage specifically, in the final stage, the questionnaire was discussed with the museums' management in order to select the motives and types of interpretation that are relevant for this type of museum. Thus, the 'fine-tuning' of the variables selection also considered their suggestions. Museum visitors were asked to grade from ' 1 ' (the less suitable) to ' 5 ' (the most suitable) different options of interpretation. A five-grade scale was also used for evaluation of agreement with the statements regarding the motivation, where ' 1 ' meant 'completely disagree' and ' 5 ' 'completely agree.' Descriptive statistics, correlations, regression models, $F$-tests and cluster analysis were employed for data processing.

\section{Results}

First, the adequacy of the type of interpretation for the whole sample was checked.

The option 'Other' was chosen by 21 interviewees, but only two specified what they had in mind ('use of sounds' and 'a lecture'). From Table 1, it is evident that live interpretation still holds the leading position, while audio guides are perceived as the least suitable. With the correlation analysis, few interesting intercon- nections were identified between the different forms of interpretation. Pearson's correlation coefficients were above 0.40 and significant at $p=0.01$ for the following pairs: 'Those which require my active involvement' 'Acted-out scenes' $(r=0.56)$, 'Those which require my active involvement' - 'Computer-supported, technologically...' $(r=0.44)$, 'Acted-out scenes' - 'Computersupported, technologically ...' $(r=0.42)$, and 'Those which require my active involvement' - 'In-person guiding' $(r=0.40)$. It seems that visitors who like personal involvement more are inclined to like combined interpretations than the others are.

\section{Motivation for Visiting the Museum}

The main motive for visiting the museums was 'To think about nature/culture' (mean 4.06; std. dev. 0.93), closely followed by 'Learning' (mean 4.00; std. dev. 1.03). 'As a supplement to other activities' (mean 3.39; std. dev. 1.25), 'Entertainment' (mean 3.28; std. dev. 1.23) and 'Just to spend some time' (mean 3.01; std. dev. 1.33) turned out to be in the middle group, while 'Staying in good company' (mean 2.86; std. dev. 1.39) and 'Nostalgia' (mean 2.21; std. dev. 1.34) were the least important as motives for coming to the museum.

Using linear regressions, how motives for visiting the museum influence the preferences of the type of interpretation were checked. The statistically significant results (at level $p=0.05$ ) are presented in Table 2 .

In-person guiding was preferred above-average by visitors who want to learn and below-average by those who came in search of entertainment. Actedout scenes seem to be more suitable for visitors who visit museums with the aim of thinking about nature or culture; somewhat logically those who come just to spend some time do not like active personal involvement. 
Table 2 Motive for Visiting the Museum as a Predictor

\begin{tabular}{llr}
\hline Dependent Variable & Independent Variable & $B($ sig.) \\
\hline In-person guiding provided by tour guides - interpreters & Learning & $0.26(0.00)$ \\
& Entertainment & $-0.12(0.02)$ \\
Acted-out scenes & To think about the nature/culture & $0.22(0.01)$ \\
Those that require my active involvement & Just to spend some time & $-0.14(0.02)$ \\
\hline
\end{tabular}

Table 3 How Motive for the Trip/Travel Influences Preferences of Interpretation

\begin{tabular}{|c|c|c|c|c|c|}
\hline Motive & $(1)$ & $(2)$ & (3) & $(4)$ & (5) \\
\hline Rest, relaxation & $4.20(0.78)$ & $3.47(1.06)$ & $3.99(0.83)$ & $3.95(1.09)$ & $3.64(1.01)$ \\
\hline Entertainment, party, experience & $3.72(0.96)$ & $3.39(0.92)$ & $3.60(1.11)$ & $3.50(1.11)$ & $3.89(0.98)$ \\
\hline Visit to relatives, friends, acquaintances & $4.15(1.18)$ & $3.26(1.20)$ & $4.00(0.67)$ & $3.53(1.39)$ & $3.42(1.26)$ \\
\hline Learning the culture and nature & $4.05(1.12)$ & $3.37(1.33)$ & $3.63(1.20)$ & $3.60(1.14)$ & $3.53(1.11)$ \\
\hline
\end{tabular}

Notes Column headings are as follows: (1) in-person guiding provided by tour guides, (2) interpreters, (3) audio guides, (4) acted-out scenes, (5) those that require my active involvement, (6) computer-supported, technologically advanced shows/displays.

Table 4 Domestic vs. Non-Domestic Visitors

\begin{tabular}{lrrrrr}
\hline Origin & $(1)$ & $(2)$ & $(3)$ & $(4)$ & $(5)$ \\
\hline Domestic & $4.23(0.99)$ & $3.23(1.24)$ & $3.82(0.98)$ & $3.70(1.23)$ & $3.59(1.12)$ \\
Non-domestic & $3.76(0.87)$ & $3.62(0.93)$ & $3.58(1.14)$ & $3.69(0.99)$ & $3.74(0.98)$ \\
\hline
\end{tabular}

Notes For column headings see Table 3.

\section{Motivation for the Trip}

The most common motives for the trip/travel among the visitors were: 'Rest, relaxation' (38\%), 'Learning about culture and nature' (30.5\%), and 'Entertainment, party, experience' (19\%). Only $6.9 \%$ stated they came to visit friends and relatives. Other motives ('business or education,' 'passing by') represented less than $5 \%$ of answers and were excluded from further analysis. With an $F$-test, the differences between these segments were checked. Mean values and standard deviations are presented in Table 3.

The $F$ test was statistically significant for 'In-person guiding provided by tour guides - interpreters' $F=$ 3.03 (sig. 0.03 ) and 'Acted-out scenes' $F=2.87$ (sig. 0.04 ). The Bonferroni test was only statistically significant (sig. 0.02) in the first column for the motives 'Rest, relaxation' and 'Entertainment, party, experience, showing that in-person guiding is considerably more appropriate for visitors with 'rest/relaxation' as the main motive for travel than for those who travel for entertainment, party and experience. This segment, together with those visitors travelling for learning the culture and nature also graded the adequacy of 'actedout scenes' lower than the rest of interviewees did.

\section{Domestic vs. non-domestic Visitors}

Approximately $29 \%$ of the interviewees were foreigners. In Table 4, comparisons between them and domestic visitors are shown.

Statistically significant differences appear in the first two columns. Domestic visitors graded in-person guiding higher than foreigners did, while the latter segment seems to prefer audio guides. Partially, this might result from a better language adaptability of audio guides compared to in-person guiding.

Very similar results were also obtained in the comparison between the segment of the first time visitors (representing $76 \%$ of the sample) and repeat visitors, as there was obviously a considerable overlap between the two segmentation criteria. Again, the only statis- 
Table 5 Comparison between Education Segments

\begin{tabular}{lrrrrr}
\hline Accomplished level of education & $(1)$ & $(2)$ & $(3)$ & $(4)$ & $(5)$ \\
\hline Elementary school or less (9\%) & $4.63(0.71)$ & $3.48(1.45)$ & $4.00(0.91)$ & $3.83(1.05)$ & $4.00(0.98)$ \\
Vocational or secondary school $(27 \%)$ & $4.01(1.13)$ & $3.34(1.16)$ & $3.84(1.05)$ & $3.42(1.36)$ & $3.55(1.20)$ \\
College, higher educ., university (58\%) & $4.08(0.90)$ & $3.35(1.12)$ & $3.69(1.02)$ & $3.76(1.07)$ & $3.54(1.13)$ \\
Master's or PhD (6\%) & $4.18(1.19)$ & $3.40(1.30)$ & $3.71(1.27)$ & $4.21(1.03)$ & $4.33(0.84)$ \\
\hline
\end{tabular}

Notes For column headings see Table 3.

tically significant difference was between in-person guiding, which was preferred by repeat visitors (mean 4.44 vs. 4.00 ) and audio guides graded higher by the first time visitors (3.46 vs. 3.05 ).

\section{Company when Travelling}

Five a priori segments were formed to check whether, during the visit of a museum, company influences the preferred type of interpretation: 'on my own' (12\%), 'with my family with children' (43\%), 'with my partner/family without children' (19\%), 'with friends' (19\%) and 'as part of an organized group' ( $7 \%$ ).

$F$-tests showed significant differences between the segments only for 'In-person guiding provided by tour guides - interpreters' ( $F=4.61$; sig. 0.00$)$. The Bonferroni test was statistically significant (in all cases $p<$ o.01) for the following pairs: 'with my family with children' (mean $=4.10) /$ 'Was part of an organized group' $($ mean $=4.86)$; 'with friends' $($ mean $=4.00) /$ 'as part of an organized group' (mean $=4.86)$; 'with my partner/family without children' (mean $=3.84$ )/'as part of an organized group' (mean $=4.86$ ). Thus, the main finding is that in-person guiding is by far the most suitable mode of interpretation for the visitors travelling in organised groups.

\section{Demographics}

For the age segments, the $F$-tests showed significant differences only for 'In-person guiding provided by tour guides - interpreters' ( $F=2.21$ sig. 0.04 ), but no Bonferroni test was statistically significant, and there was no evident pattern present. Furthermore, no significant differences were detected among the 'income' segments.

In Table 5, mean values with standard deviations are presented for the segments based on visitors' education. Significant differences between the segments are apparent for 'in-person guiding' $(F=2.64$; sig. $0.05)$, 'active involvement' $(F=3.03$; sig. 0.03$)$ and 'computer-supported shows/displays' $(F=4.31$; sig. o.o1). Furthermore, Bonferroni tests were statistically significant for:

- 'In-person guiding,' which is strongly preferred by the segment 'elementary school or less' in comparison to 'vocational or secondary school;'

- 'Those that require my active involvement,' which is more appropriate for the segment 'master's or PhD' than for 'vocational or secondary school;'

- 'Computer-supported, technologically advanced shows/displays,' which is again above average preferred by the segment 'master's or PhD.'

\section{Cluster Analysis}

Finally, an a posteriori approach based on visitors' preferences regarding the types of interpretation was employed for segmentation of the sample. In the first phase, potential outliers by hierarchical analysis were sought. After the exclusion of one case, several options of cluster numbers were checked; three clusters turned out to be the most sensible solution, as they formed clearly distinct segments, especially in terms of motivation and company on the travel. In Table 6, the characteristics of cluster members are shown.

The largest segment is 'Families with children.' These visitors are relatively unproblematic regarding the type of interpretation. Their main motive is, in fact, spending time with their children. They graded 'Entertainment' (mean 3.48) and 'supplement to other activities' (mean 3.63) as motives to come to the museum significantly above the average.

The second segment represents a quarter of the sample. These visitors are the most 'serious.' 'Just to spend some time' (mean 2.50) and 'Entertainment' are 
Table 6 A Posteriori Segments

\begin{tabular}{|c|c|c|c|}
\hline Cluster & 'Families with children' (45\%) & 'Domestic visitors' (24\%) & $\begin{array}{l}\text { 'Couples who love } \\
\text { entertainment' (31\%) }\end{array}$ \\
\hline $\begin{array}{l}\text { Preferred type of } \\
\text { interpretation }\end{array}$ & $\begin{array}{l}\text { All are quite acceptable } \\
\text { (mean values } 4.17-4.28 \text { ) }\end{array}$ & $\begin{array}{l}\text { In-person guiding (mean } \\
4.57 \text { ) }\end{array}$ & $\begin{array}{l}\text { They do not care (mean } \\
\text { values } 2.45-3.31 \text { ) }\end{array}$ \\
\hline Non suitable interpretation & None & Audio-guides (mean 2.07) & $\begin{array}{l}\text { With active involvement } \\
\text { (mean 2.45) }\end{array}$ \\
\hline Foreigners & $48 \%$ & $5 \%$ & $35 \%$ \\
\hline Repeat visitors & $22 \%$ & $34 \%$ & $19 \%$ \\
\hline Salient motive for the travel & $\begin{array}{l}\text { Rest, relaxation, good } \\
\text { company }\end{array}$ & Learning, vFR & Entertainment \\
\hline Company on travel & Family with children & $\begin{array}{l}\text { Mixed, a bit more often with } \\
\text { organised group }\end{array}$ & With partner \\
\hline Other conspicuous features & Younger & $\begin{array}{l}\text { Repeat visitors, a bit below } \\
\text { average education, stay longer }\end{array}$ & $\begin{array}{l}\text { First-time visitors, stay short } \\
\text { time }\end{array}$ \\
\hline
\end{tabular}

less important motives (mean 2.98) for a visit than in the other two segments. They are mostly domestic, quite heterogeneous visitors. The personal approach is found to be by far the most suitable way of interpretation for this segment.

The last segment seems to be to a considerable extent compound by 'accidental', not very interested visitors with no specific motive for visiting the museum. 'To spend some time' as a motive for visiting the museum stands out a bit from the average. They do not like any exertion or serious involvement during the visit.

\section{Framework for Identifying Market Segments Based on Visitors' Preferences for Interpretation}

As suggested by Wearing et al. (2008), from the data obtained, a framework is developed to illustrate the order of actions required to determine the most suitable type of interpretation for the specific market segment. By isolating and analysing interpretation variables and visitor variables associated with visitor interpretation preferences, the framework (Figure 1) shows the order of actions required to determine the museum market segments.

This framework shows the process of identification of certain variables that are consistent with particular types of interpretation that relate to visitors' preferences. As a posteriori segmentation offers more complex, multidimensional definition of segments than $a$

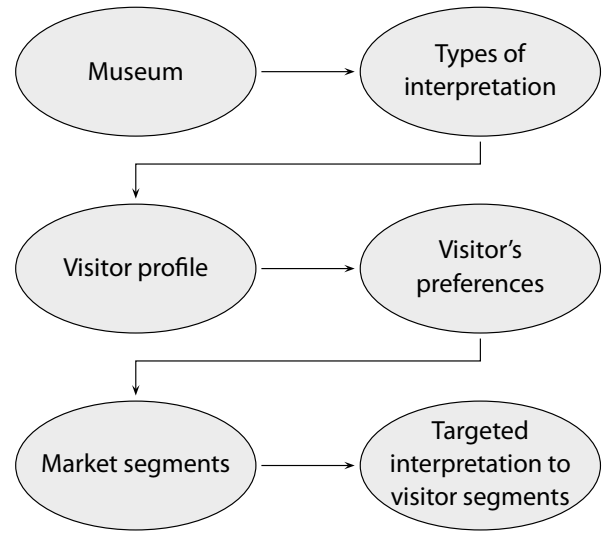

Figure 1 Identifying Visitor and Interpretation Variables and Market Segments (adapted from Wearing et al., 2008, p. 10)

priori approach, we have chosen the former as the basis for the model formation.

Mean values of single interpretation mode preferences were split into three categories - from the less preferred (denoted by one asterisk) to the most preferred (denoted by three asterisks). Since there was no mean value below 2.00, the categories were 2.00$2.99,3.00-3.99$, and 4.00-5.00. Once these variables are identified, effective museum interpretation may be applied to enhance the target visitors' experience (Table 7).

Tables that list market segments and correspond- 
Table 7 Interpretation Recommendations for Museums Target Markets

\begin{tabular}{|c|c|c|c|c|c|}
\hline Market segment & (1) & (2) & (3) & (4) & (5) \\
\hline Families with children & $* * *$ & $* * *$ & $* * *$ & $* * *$ & $* * *$ \\
\hline Domestic visitors & $* * *$ & * & ** & $* * *$ & ** \\
\hline Couples who love entertainment & ** & $* *$ & * & * & * \\
\hline
\end{tabular}

Notes Column headings are as follows: (1) in-person guiding, (2) audio-guiding, (3) acting-out scenes, (4) active involvement, (5) computer support.

ing interpretation variables may be very useful for museum managers in deciding what interpretation variables to incorporate into their programs for target market segments. For example, if the first two segments are identified as target market segments, taking into account the key visitors' preferences, the results suggest that in-person guiding and active involvement are the most preferred, followed by computer support and acting-out scenes, while audio-guiding is the least suitable interpretation mode.

\section{Discussion}

This study has aimed to develop a framework that would enable initiatives in interpretation to enhance visitor experiences for museums' target markets. Previous studies have mainly focused on behaviour, experiences, attitudes and opinions of actual and potential visitors. In contrast, this study has focused on the identification of market segments in connection with their preferences of distinct types of interpretation for natural heritage museums.

In the first part of the analysis, we identified differences between several a priori market segments in terms of preferences regarding interpretation modes. Socio-demographic (age, income, education), psychographic (motivation for travel and museum visit) and behavioural (company on the travel, previous visits) variables were employed for this purpose. Visitor profiles were similar to that of other findings (e.g. Griffin \& Archer, 2001; Wearing et al., 2008; Macdonald, 2011). Our study confirmed that museum visitors were in the upper education ( $59 \%$ with college or university degree and $5 \%$ with master's or $\mathrm{PhD}$ ), economically active ( $43 \%$ employed and $42 \%$ students), average and above average income groups ( $85 \%)$, looking for opportunities to learn about the nature and culture, entertainment and staying in good company.
The results of a priori segmentation showed that some demographic and psychographic traits have stronger links to interpretation variables than others. Even though computer-based interpretations have nowadays become almost an indispensable part of exhibitions (Rentschler \& Hede, 2007), our results show that in-person guiding provided by tour guidesinterpreters remains the most preferred mode of interpretation of natural heritage museums contents in the Adriatic area. Comparisons between a priori segments revealed this approach is by far the most suitable for the visitors travelling in organised groups, those whose main motive for travel is resting and relaxation and visitors coming to museums with the main aim to learn. The larger part of these are domestic and repeat visitors. Computer-supported and technologically advanced displays and audio guides as two representatives of impersonal interpretation were, in fact, ranked last, indicating that technological solutions, for now, cannot satisfactorily replace human presence in museums. The preferred mode of interpretation is par for the course linked to the degree of willingness of visitors' personal involvement. Those with higher willingness tend to seek deeper experience (McKercher, 2002) and have clear ideas of what they want to see, learn and experience during the visit. According to our findings, these visitors are inclined to like combined interpretations. Interestingly, no clear pattern was detected regarding how the age of visitors influences preferred types of interpretation.

In the second part of the analysis, we adopted $a$ posteriori segmentation to identify key segments that were included in the model/framework, showing the most suitable type of interpretation for specific market segments of participating museums. With cluster analysis, three distinct market groups were identified. They were named: 'Families with children,' 'Domes- 
tic visitors' and 'Couples who love entertainment.' Of course, as this is usually the case in a posteriori segmentation, one has to bear in mind that a considerable amount of simplification had to be used in segments' description. Nevertheless, huge differences appeared between them in terms of interpretation type preferences. While the first and the biggest segment, 'Families with children' ( $45 \%$ ), is very eager to learn and experience the museum through all types of interpretation, the third segment, 'Couples who love entertainment,' seems to be quite satisfied without any explicit interpretation at all. In our sample, this segment represents almost one third of all visitors.

The results suggest the adoption of specific policies for heritage museums included in the research to improve visitor experience through interpretation. By implementing the proposed framework, managers are now able to select relevant interpretation modes that correspond to key target markets. By concentrating on different interpretation needs and modes, museum managers can apply visitor driven approaches not only to a museum exhibit but also to museum interpretation.

\section{References}

Apostolakis, A. (2003). The convergence process in heritage tourism. Annals of Tourism Research, 30(4), 795-812.

Bitgood, S., \& Dukes, S. (2006). Interest and effort as predictors of reading: A test of the general value principle. Current Trends in Audience Research, 19. Retrieved from: http://www.jsu.edu/psychology/docs/ao5-Interest_ _Effort.pdf

Blattberg, R. C., \& Broderick, C. J. (1991). Marketing of art museums. Chicago, IL: University of Chicago Press.

Cohen, E. (1979). Rethinking the sociology of tourism. Annals of Tourism Research, 6(1), 18-35.

Chen, H. C., Chuan K. H., \& Ming C. H. (2006, 2-4 November). A new communication model in the natural history museum. Paper presented at the INTERCOM conference, Taipei, Taiwan.

Dolnicar, S. (2002). Activity-based market sub-segmentation of cultural tourists. Journal of Hospitality and Tourism Management 9(2), 94-105.

Dudley, S. H. (2010). Museum materialities: Objects, engagements, interpretations. London, England: Routledge.

Falk, J. H. (2013). Understanding visitors' motivations and learning. In I. Lundgaard Braendolt \& J. T. Jensen (Eds.),
Museums social learning spaces and knowledge producing processes (pp. 106-127). Copenhagen, Denmark: Danish Agency for Culture.

Goulding, C. (200o). The museum environment and the visitor experience. European Journal of Marketing, 34(3/4), 261-278.

Groote, P., \& Haartsen, T. (2016). The communication of heritage: Creating place identities. In B. Graham, \& P. Howard (Eds.), The Ashgate research companion to heritage and identity (pp. 181-194). London, England: Routlege.

Ham, H. S. (1992). Environmental interpretation: A practical guide for people with big ideas and small budgets. Golden, co: North American Press.

Hooper-Greenhill, E. (1994). Museums and their visitors. London, England: Routledge.

Hughes, L. H. (2002). Culture and tourism: A framework for further analysis. Managing Leisure, 7(3), 164-175.

Jewell, B., \& Crotts, J. C. (2002). Adding psychological value to heritage tourism experiences. Journal of Travel and Tourism Marketing, 11(4), 13-28.

Keene, S. (2005). Museums and the interpretation of visual culture. Material Religion, 1(2), 281-282.

Kirshenblatt-Gimblett, B. (1998). Destination culture: Tourism, museums, and heritage. Berkeley, cA: University of California Press.

Koran, J. J., \& Koran, M. L. (1986). A proposed framework for exploring museum education research. The Journal of Museum Education, 11(1), 12-16.

Kotler, G. N., Kotler, P., \& Kotler, W. I. (2008). Museum marketing and strategy. San Francisco, CA: Jossey-Bass.

Macdonald, S. (2011). A companion to museum studies. New York, Ny: Wiley-Blackwell.

Maier, E. (1999). Will online images prove to be a multimedia cornucopia for museums? Aslib Proceedings, 51(10), 325334.

Marstine, J. (2008). New museum theory and practice: An introduction. Oxford, Englandd: Blackwell.

McKercher, B. (2002). Towards a classification of cultural tourists. International Journal of Tourism Research, 4(1), 29-38.

McLean, F. (1997). Marketing the museum. London, England: Routledge.

Moscardo, G., Fesenmaier, D. R., Uysal, M., \& Joseph T. O. (1999). Making visitors mindful: Principles for creating sustainable visitor experiences through effective communication. Champaign, IL: Sagamore.

Noor, S. M., Mostafa, R. S., Vithya, G., \& Mastura, J. (2015). Effective interpretation using various media toward 
mindfulness: A case study of Malacca. Journal of Heritage Tourism, 10(3), 263-279.

Packer, J., \& Ballantyne, R. (2002). Motivational factors and the visitor experience: A comparison of three sites. $\mathrm{Cu}$ rator: The Museum Journal, 45(3), 183-198.

Plog, S. (2001). Why destination areas rise and fall in popularity: An update of a Cornell Quarterly classic. Cornell Hotel and Restaurant Administration Quarterly, 42, 1324.

Poon, A. (1998). Tourism, technology and competitive strategies. Wallingford, England: CA B I.

Poria, Y., Butler, R., \& Airey, D. (2004). Links between tourists, heritage, and reasons for visiting heritage sites. Journal of Travel Research, 43, 19-28.

Poria, Y., Reichel, A., \& Biran, A. (2006). Heritage site management: Motivations and expectations. Annals of Tourism Research, 33(1), 162-178.

Rentschler, R., \& Hede, A. M. (2007). Museum marketing: Competing in the global marketplace. Oxford, England: Butterworth-Heinemann.

Roppola, T. (2012). Designing for the museum visitor experience. New York, NY: Routledge.

Rounds, J. (2004). Strategies for the curiosity-driven museum visitor. Curator: The Museum Journal, 47(4), 389412.

Silberberg, T. (1995). Cultural tourism and business opportunities for museums and heritage sites. Tourism Management, 16(5), 361-365.

Silverman, H. L. (1995). Visitor meaning-making in museums for a new age. Curator: The Museum Journal, 38(3), 161-170.
Staiff, R. (2014). Re-imagining heritage interpretation. Farnham, England: Ashgate.

Stylianou-Lambert, T. (2011). Gazing from home: Cultural tourism and art museums. Annals of Tourism Research, 38(2), 403-421.

Thyne, M. (2001). The importance of values research for nonprofit organisations: The motivation-based values of museum visitors. International Journal of Nonprofit and Voluntary Sector Marketing, 6(2), 116-130.

Tilden, F. (1977). Interpreting our heritage (3rd ed.). Chapel Hill, NC: University of North Carolina Press.

Todd, S., \& Lawson, R. (2001). Lifestyle segmentation and museum/gallery visiting behavior. International Journal of Nonprofit and Voluntary Sector Marketing, 6(3), 269277.

Trinh, T. T., \& Ryan, C. (2013). Museums, exhibits and visitor satisfaction: A study of the Cham Museum, Danang, Vietnam. Journal of Tourism and Cultural Change, 11(4), 239-263.

Wearing, S., Edinborough, P., Hodgson, L., \& Frew, E. (2008). Enhancing visitor experience through interpretation: $A n$ examination of influencing factors. Gold Coast, Australia: CRC for Sustainable Tourism.

This paper is published under the terms of the Attribution- NonCommercial-NoDerivatives 4.0 International (CC B Y-NC-ND 4.0) License. 